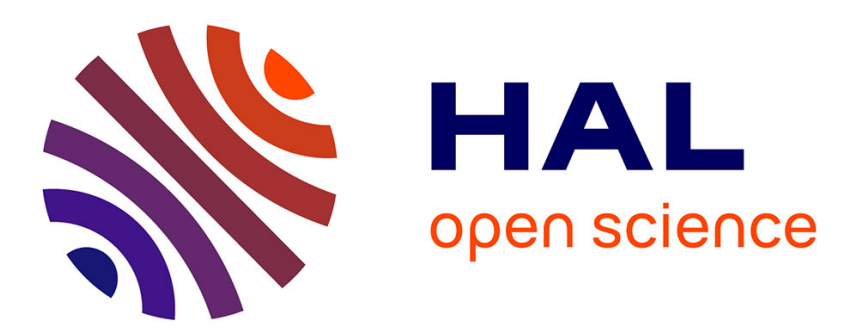

\title{
Influence of the water saturation level on phosphorus retention and treatment performances of vertical flow constructed wetland combined with trickling filter and FeCl3 injection
}

Boram Kim, Mathieu Gautier, Pascal Molle, Philippe Michel, Rémy Gourdon

\section{To cite this version:}

Boram Kim, Mathieu Gautier, Pascal Molle, Philippe Michel, Rémy Gourdon. Influence of the water saturation level on phosphorus retention and treatment performances of vertical flow constructed wetland combined with trickling filter and FeCl3 injection. Ecological Engineering, 2015, 80, pp.5361. 10.1016/j.ecoleng.2014.09.097 . hal-01302485

\author{
HAL Id: hal-01302485 \\ https://hal.science/hal-01302485
}

Submitted on 14 Apr 2016

HAL is a multi-disciplinary open access archive for the deposit and dissemination of scientific research documents, whether they are published or not. The documents may come from teaching and research institutions in France or abroad, or from public or private research centers.
L'archive ouverte pluridisciplinaire HAL, est destinée au dépôt et à la diffusion de documents scientifiques de niveau recherche, publiés ou non, émanant des établissements d'enseignement et de recherche français ou étrangers, des laboratoires publics ou privés. 


\section{Influence of the water saturation level on}

phosphorus retention and treatment performances of vertical flow constructed wetland combined with trickling filter and $\mathrm{FeCl}_{3}$ injection

Boram Kim*, Mathieu Gautier*, Pascal Molle, Philippe Michel, and Rémy Gourdon

\section{$\rightarrow$ To cite this version:}

Boram Kim, Mathieu Gautier, Pascal Molle, Philippe Michel, and Rémy Gourdon. Influence of the water saturation level on phosphorus retention and treatment performances of vertical flow constructed wetland combined with trickling filter and $\mathrm{FeCl}_{3}$ injection. Ecol. Eng. 2015, 80, pp 53-61.

Please contact the corresponding authors $(*)$ if you are interested by a copy of the article published in the journal. 
Influence of the water saturation level on phosphorus retention and treatment performances of vertical flow constructed wetland combined with trickling filter and $\mathrm{FeCl}_{3}$ injection

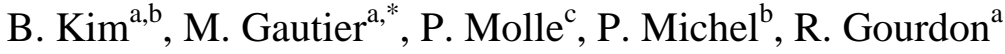 \\ ${ }^{a}$ University of Lyon, INSA Lyon, LGCIE - DEEP, 20 av. A. Einstein, Villeurbanne cedex, F- \\ 69621, France \\ ${ }^{b}$ SCIRPE, Society of design and production engineering for wastewater purification, 5 Allée \\ Alban Vistel, Sainte Foy Lès Lyon, F-69110, France \\ ${ }^{c}$ IRSTEA, UR MALY, 5 rue de la Doua, F-69100 Villeurbanne, France \\ * Corresponding author. \\ E-mail address: $\quad$ mathieu.gautier@insa-lyon.fr \\ Address: $\quad$ LGCIE - DEEP Site Carnot \\ 20 av. A. Einstein \\ F-69621 Villeurbanne Cedex \\ Tel.: $\quad+33(0) 472438348$
}




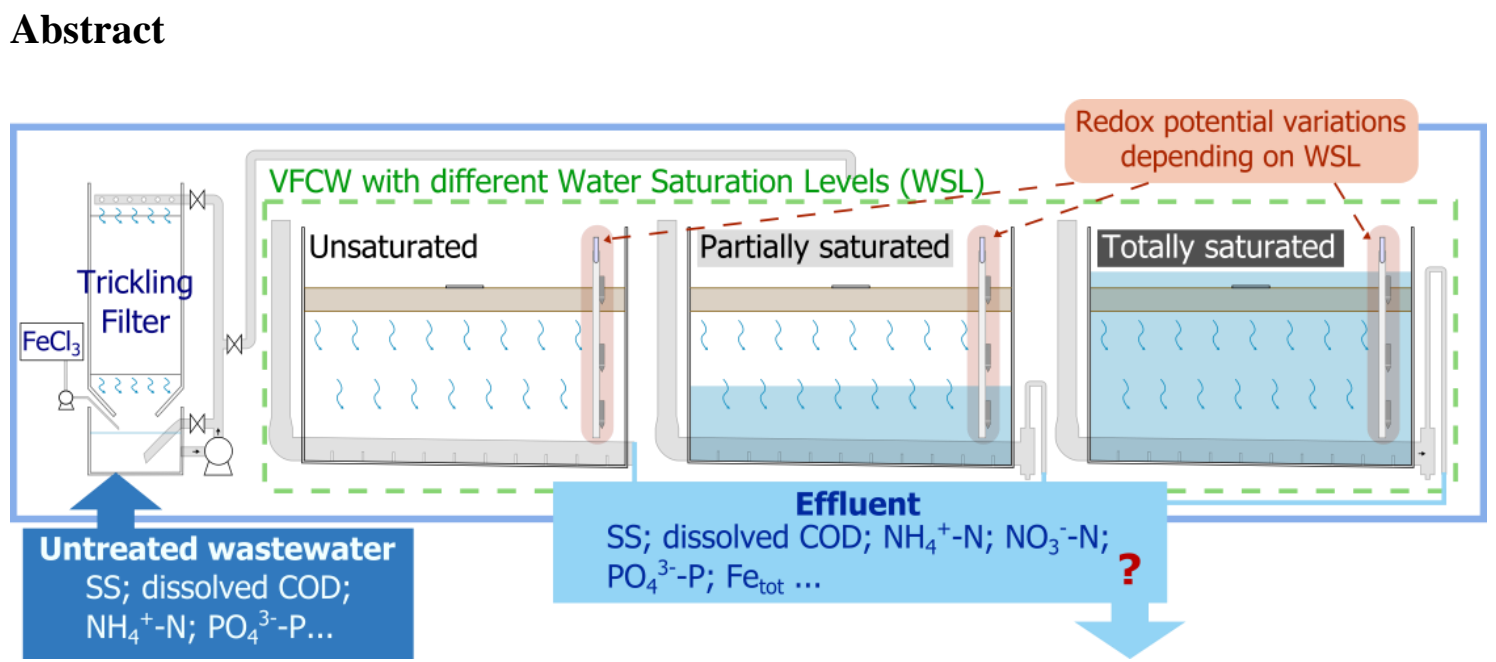

The aim of the study was to determine the effects on treatment efficiency of oxidationreduction (redox) conditions that are caused by different water saturation levels within vertical-flow constructed wetlands (VFCW), with specific attention to phosphorus (P) retention. The study was conducted by monitoring over 18 weeks a pilot-scale system consisting of a biological aerobic trickling filter as a biological pre-treatment step, followed by ferric chloride $\left(\mathrm{FeCl}_{3}\right)$ addition for phosphate removal and a stage of VFCW. By adjusting the water saturation level, the VFCW was operated successively under fully unsaturated, partly saturated, completely saturated (flooded), and then again unsaturated conditions. Redox potentials (Eh) were measured at three different levels within the VFCW. Results revealed that Eh was logically affected by the water-saturation level and the feeding-resting periods. Treatment efficiency was very good under fully unsaturated and partly saturated conditions. Under flooded conditions, the performance of the filter declined when the flood was maintained for around one week. However, VFCW regained its previous efficiency after the effluent was drained out and aerobic conditions were restored, indicating that the system was resistant and robust enough that periodical flooding did nott affect its performance afterwards.

Keywords: vertical flow constructed wetland; trickling filter; ferric chloride coagulation; redox potential; phosphorus 


\section{Introduction}

Raw domestic wastewater treatment by vertical flow constructed wetlands (VFCW) has become very well developed in small communities in France (Molle et al., 2006; Torrens et al., 2009). Numerous studies have proven the efficiency of the system in carbon removal and nitrification (Abou-Elela et al., 2013; Brix and Arias, 2005; Kadlec et al., 2000). Other authors introduced various alternative compact systems (Heistad et al., 2006; Prigent et al., 2013) or highlighted some limitations of VFCWs such as low denitrification rate and poor phosphorus removal (Prochaska et al., 2007; Verhoeven and Meuleman, 1999). Indeed, the release of nitrates and phosphorus into sensitive aquatic ecosystems may promote eutrophication (Lowe and Keenan, 1997; Schindler, 1977; Tiessen, 2008), and therefore phosphorus $(\mathrm{P})$ and total nitrogen $(\mathrm{TN})$ concentrations in the treated effluents must satisfy increasingly low regulatory limits.

In order to improve $\mathrm{TN}$ and $\mathrm{P}$ removal, various combined processes and tertiary treatments were developed. Hybrid systems combining vertical and horizontal flow (HF) constructed wetlands were investigated for $\mathrm{TN}$ removal by successive nitrification and denitrification (Molle et al., 2008; Vymazal, 2005). Good efficiencies were obtained but with increased environmental footprint. Regarding phosphorus removal, most studies investigated systems using various filter media with high phosphorus sorption capacity (Martín et al., 2013; Molle et al., 2011; Vohla et al., 2011). Although very efficient, these approaches may not provide cheap and durable solutions on a long term.

An alternative approach, the AZOE-NP ${ }^{\circledR}$ process, was developed by the French company SCIRPE (EP1857419A1; WO2012150296). The treatment line combines (i) a screening at $3 \mathrm{~mm}$ mesh, (ii) a biological aerobic trickling filter, (iii) ferric chloride $\left(\mathrm{FeCl}_{3}\right)$ addition for dissolved phosphate removal and (iv) two stages of partly saturated VFCWs. The use of a trickling filter as a first biological treatment step allows to reduce the required surface of 
VFCW down to a maximum of $1.5 \mathrm{~m}^{2}$ per Population-Equivalent (PE) as compared to $2 \mathrm{~m}^{2}$ in the general operational recommendations in France for classical two-stage VFCWs (Molle et al., 2005).

One of the particularities of the AZOE-NP ${ }^{\circledR}$ system is the succession of different levels of redox conditions along the process line. Firstly, the trickling filter is passively aerated by its bottom part and therefore stimulated aerobic microbial processes such as nitrification. Then, within each VFCW stage, the upper zone is not saturated and therefore aerobic, whereas the lower zone is saturated with anoxic conditions allowing denitrification process to occur. The depth of the saturated zone can be adjusted to optimize TN removal efficiency. Another particularity of the AZOE-NP ${ }^{\circledR}$ process concerns phosphorus removal. Dissolved reactive $\mathrm{P}$ is firstly precipitated by $\mathrm{FeCl}_{3}$ injection at the outflow of the trickling filter. The particulate forms of $\mathrm{P}$ are subsequently retained by filtration though the first stage of VFCW (Kim et al., 2013). The deposits, which progressively accumulate at the surface of VFCW, are usually removed every 10-15 years.

Redox conditions are known to influence microbial processes within constructed wetlands (Laanbroek, 1990; Reddy and D'Angelo, 1997). In the case of the AZOE-NP ${ }^{\circledR}$ process, redox conditions may affect the fate of the ferric species within the VFCW, and consequently the behaviour of $\mathrm{P}$ species associated to them. However, no study actually measured Eh levels within the granular medium in VFCW (Faulwetter et al., 2009). In this study, a pilot-scale VFCW was implemented to monitor Eh at three different depths within the porous medium with the objectives to determine (i) the influence of VFCW saturation level on the performances of the system and (ii) the effects of Eh within the VFCW on the retention of phosphorus.

\section{Materials and methods}




\subsection{Description of pilot's design}

Pilot-scale unit of VFCW was installed within a greenhouse in Irstea's experimental hall located at La Feyssine in the metropolitan area of Lyon (France). A schematic diagram of pilot-scale installation is shown in Fig. 1. This experimental setup is meant to simulate the operational units of a real-scale AZOE-NP ${ }^{\circledR}$ plant but focused only on the first stage of filters as previous studies had shown that the efficiency of the process mainly occurred within the $1^{\text {st }}$ stage (Kim et al., 2012).

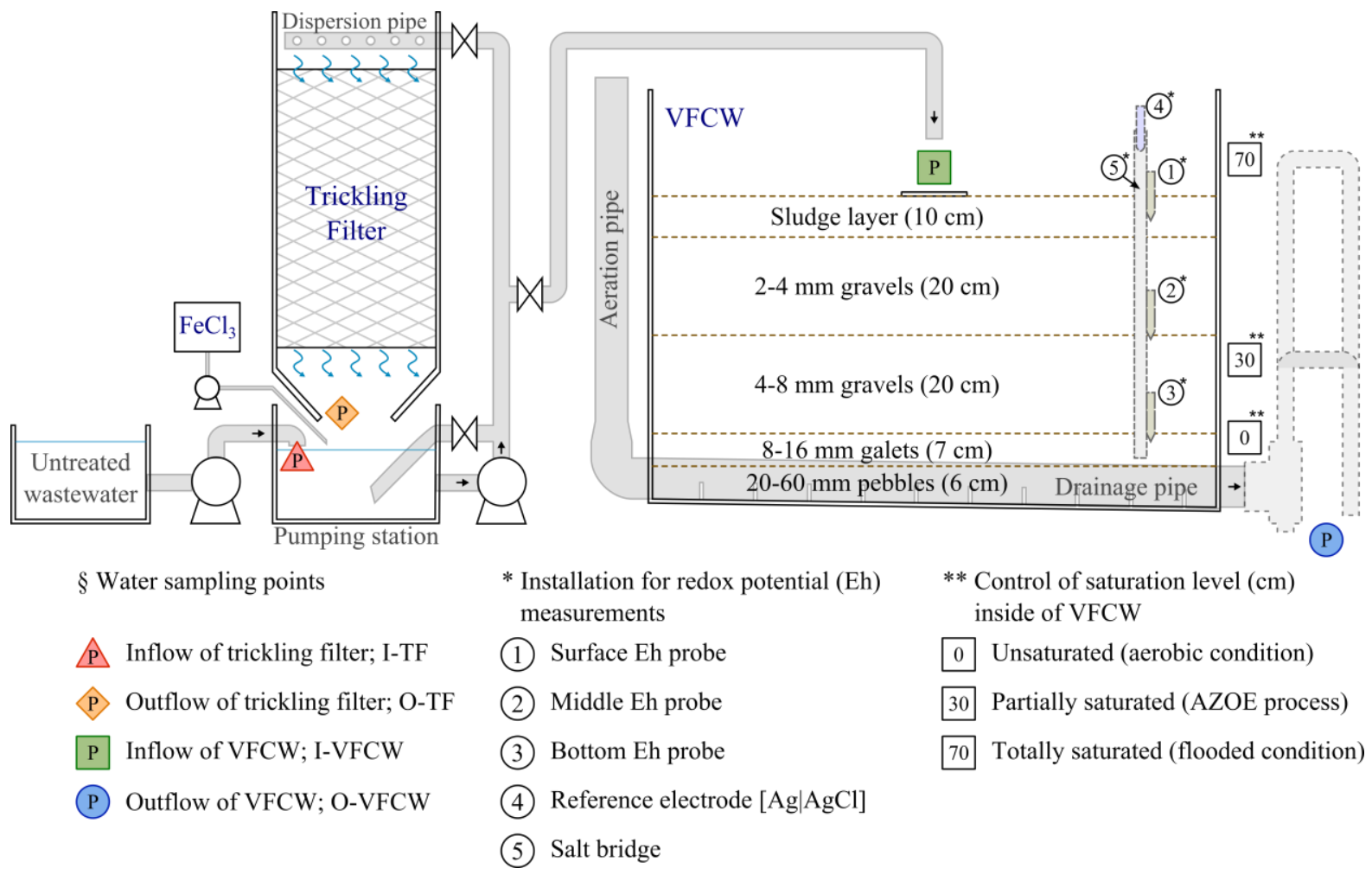

Fig. 1. Simplified diagram of pilot-scale installation.

The pilot-scale system was designed as a combination of four sub-units as shown in Fig. 1:

1) A pumping station used for the successive following treatment steps: collection of screened wastewaters, feeding of trickling filter in a closed loop mode, mixing of the solution after ferric chloride injection, and injection of the solution at the surface of the VFCW. 
2) A pilot-scale trickling filter of $0.29 \mathrm{~m}^{3}$ fully packed with cross flow plastic media (ordered) developing a specific surface area of $200 \mathrm{~m}^{2} \cdot \mathrm{m}^{-3}$.

3) A dosing pump (DDE, Grundfos) for ferric chloride injection.

4) A pilot-scale VFCW with a surface of $2 \mathrm{~m}^{2}$ and a depth of $0.7 \mathrm{~m}$. It was filled with 4 successive layers of granular materials which were taken from a real scale AZOE-NP ${ }^{\circledR}$ system in operation since 8 years: a $20 \mathrm{~cm}$ upper filtration layer was made of $2-4 \mathrm{~mm}$ gravels; two intermediate layers $(20 \mathrm{~cm}$ with $4-8 \mathrm{~mm}$ gravels and $7 \mathrm{~cm}$ with $8-16 \mathrm{~mm}$ gravels) and a $6 \mathrm{~cm}$ lower drainage layer made of 20-60 $\mathrm{mm}$ pebbles, corresponding to two thirds of the real-scale plant depth. The pilot was also equipped with a siphon to adjust the water saturation level. In addition, a layer of $10 \mathrm{~cm}$ of surface deposit sludge (sampled from the real scale plant) was disposed at the top surface of the VFCW. The characteristics of the sludge deposit were described in a previous study (Kim et al., 2013). Finally, 8 young common reeds (Phragmites australis) per square meter were planted in the surface deposit layer.

\subsection{Description of pilot's operation}

The pilot system was fed with real domestic wastewater obtained directly from the nearby wastewater treatment plant of La Feyssine. To reduce the risks of clogging of the distribution pipes however, wastewater was passed through a $1 \mathrm{~mm}$ sieve before being used. The pilot system was then operated automatically as described below.

Sieved wastewater was introduced into the pumping station's tank. The feeding pump was started to feed the trickling filter downward in a closed-loop mode. Large openings in the top and bottom of the bioreactor allowed a good circulation of air though the packing medium. When a pre-determined volume $(50 \mathrm{~L})$ of wastewater was reached in the pumping station, the trickling filter's feeding was stopped and the pre-treated water was drained into the pumping 
station's tank. The desired volume $(7.0 \mathrm{~mL})$ of a 574 g.L $\mathrm{L}^{-1}$ ferric chloride aqueous solution was then precisely injected into the tank with a dosing pump, corresponding to a total added iron concentration of $0.45 \mathrm{mmol} . \mathrm{L}^{-1}$ within the tank. The mixture was mixed by closed-loop circulation within the tank using the feeding pump. Finally, the content of the tank was spread at the surface of the VFCW using the feeding pump through one feeding pipe positioned in the centre part of the VFCW.

\subsection{Experimental protocol}

The trickling filter pilot was put in operation 2 months before the beginning of the experiments, to reach stable biological conditions, with a continuous feeding of $0.9 \mathrm{~m}^{3}$.day ${ }^{-1}$. The VFCW pilot was then operated by alternating feeding periods of $1 / 3$ of week and resting periods of $2 / 3$ of week in order to simulate the operational conditions of real scale systems. In order to study the influence of redox conditions on performance of the system, particularly phosphorus retention, investigations were done with three different water-saturation levels within the VFCW: (1) unsaturated phase $[0 \mathrm{~cm}]$ corresponding to a free drainage with no effluent resting at the bottom of the filter; (2) partly saturated phase [30 $\mathrm{cm}]$ corresponding to the classical mode of operation of AZOE-NP ${ }^{\circledR}$ process, and (3) saturated phase $[70 \mathrm{~cm}]$ where the water level was set to completely flood the filter. During the first phase of the study, aeration within VFCW was possible from the top and the bottom. During the second phase, aeration would be only provided form the top of the filter, resulting in the establishment of aerobic conditions in the $23 \mathrm{~cm}$ upper part and a $30 \mathrm{~cm}$ anoxic to anaerobic lower zone. The last phase of the study, where even the surface deposit sludge layer was flooded, would correspond to extreme conditions resulting from a malfunctioning of the wastewater collect system during long and heavy raining period. 
The study started under unsaturated condition (first phase) which was monitored over 6 weeks. The second phase (partly saturated conditions) was then implemented for 6 weeks as well, followed by the last phase (totally saturated also called flooded conditions) which was only conducted over 4 weeks because of the extreme condition. Finally, the effluent was drained out of the VFCW pilot to monitor over 2 more weeks the re-establishment of aerobic conditions and thereby investigate the resilience of the system.

\subsection{Sampling and analyses}

Influent and effluent samples were taken twice a week at the beginning and the end of each feeding period of the VFCW pilot. Four sampling points were monitored, namely: (i) inlet of trickling filter (sieved wastewater) [I-TF], (ii) outlet of trickling filter (before ferric chloride injection) [O-TF], (iii) inlet of VFCW (after ferric chloride injection) and (iv) outlet of VFCW stage.

Each sample was immediately divided into two aliquots. The first aliquot was analysed for total suspended solids (TSS) according to French standard methods (AFNOR, 2005). The second aliquot of each sample was immediately filtered through $0.45 \mu \mathrm{m}$ syringe filter (Sartorius Minisart). The filtrate was stored at $4{ }^{\circ} \mathrm{C}$ for a maximum of $6 \mathrm{~h}$ before being analyzed as follows. Dissolved chemical oxygen demand (dCOD) was photometrically determined after sample oxidation with a hot sulphuric solution of potassium dichromate (analogous to standard methods ISO 15705; C4/25 and C3/25 cell tests; WTW). Ammonium and nitrate were analyzed by colorimetric techniques (14739 and 114542 cell tests; WTW). Dissolved reactive phosphorus (DRP) was analyzed by the colorimetric molybdenum blue method (Murphy and Riley, 1962). Total soluble elemental concentrations (Fe, Ca, Al, Mn and $\mathrm{Si}$ ) were determined by ICP-AES (Ultima 2; Horiba JobinYvon SAS). Sulphate and 
chloride concentrations were determined by ion chromatography using a Dionex Ion Pac ${ }^{\circledR}$ AS17C column preceded by an AG17 guard-column.

Redox conditions within the VFCW pilot were monitored by a method described by Veneman and Pickering (1983) using redox probes and the salt bridge. The salt bridge was made by filling $1.25 \mathrm{~cm}$ diameter Plexiglas ${ }^{\circledR}$ pipes with saturated $\mathrm{KCl}$ agar-agar gel (3\%). The gel was spiked with phenol to prevent microbial growth within the salt bridge. The top part of the salt-bridge pipe received a single junction $\mathrm{Ag} / \mathrm{AgCl}(\mathrm{KCl} 3 \mathrm{M})$ reference electrode and the bottom of the tube was sealed. On the salt bridge tube, three 6-mm diameter holes were drilled face to the placements of each platinum electrode and covered with filter paper to maintain the gel inside. Three platinum electrodes were placed in the VFCW pilot respectively at $10 \mathrm{~cm}, 34 \mathrm{~cm}$ and $58 \mathrm{~cm}$ from the bottom. The salt bridge was installed close to the Pt electrodes. Redox potentials were taken every five minutes using a potentiometer (Consort; C861) which was connected to the Pt and reference electrodes. Recorded redox potential values $\mathrm{Eh}_{\mathrm{m}}$ were then expressed with respect to the standard hydrogen electrode (SHE) reference using the following equation:

$$
\mathrm{Eh}=\mathrm{Eh}_{\mathrm{m}}+222 \mathrm{mV}
$$

where $\mathrm{Eh}$ is the corrected value of redox potentials in $\mathrm{mV}$ with respect to $\mathrm{SHE}$, and $\mathrm{Eh}_{\mathrm{m}}$ is the experimental reading in $\mathrm{mV}$ with respect to the $\mathrm{Ag} / \mathrm{AgCl}$ reference. Though the SHE correction factor is temperature dependent, corrections were not made as the error resulting from the variation of temperature in the study was considered negligible as compared to other experimental uncertainties. No supplementary $\mathrm{pH}$ correction was made because $\mathrm{pH}$ measurements at inlet/outlet of the VFCW pilot were close to neutrality $(7.20 \pm 0.34)$.

\subsection{Statistical data analyses}


The $95 \%$ confidence interval was determined by means values \pm 1.96 times standard error of the mean (SEM), which was calculated as the standard deviation (SD) divided by the square root of the sample size. For data analyses and visualisation, ANalysis Of VAriance (ANOVA, least significant differences [LSD] at $\mathrm{p}<0.05$ level), Pearson correlation coefficients and Principal Component Analysis (PCA) were performed using the R software package v 3.0.2.

\section{Results and discussion}

The average concentrations of measured parameters at different steps of the treatment line are gathered in Table 1. Results are shown below in terms of inlet and outlet concentrations measured at each individual step of the treatment line, in order to evaluate their respective contribution to the performance of the whole treatment line. The major focus is made on the monitoring of the VFCW stage and the effect of its mode of operation on $\mathrm{P}$ retention.

3.1. Effect of water saturation level in VFCW on the overall performance of the treatment line

Treatment performances with respect to each parameter were calculated in the form of "(inlet-outlet)/ inlet"

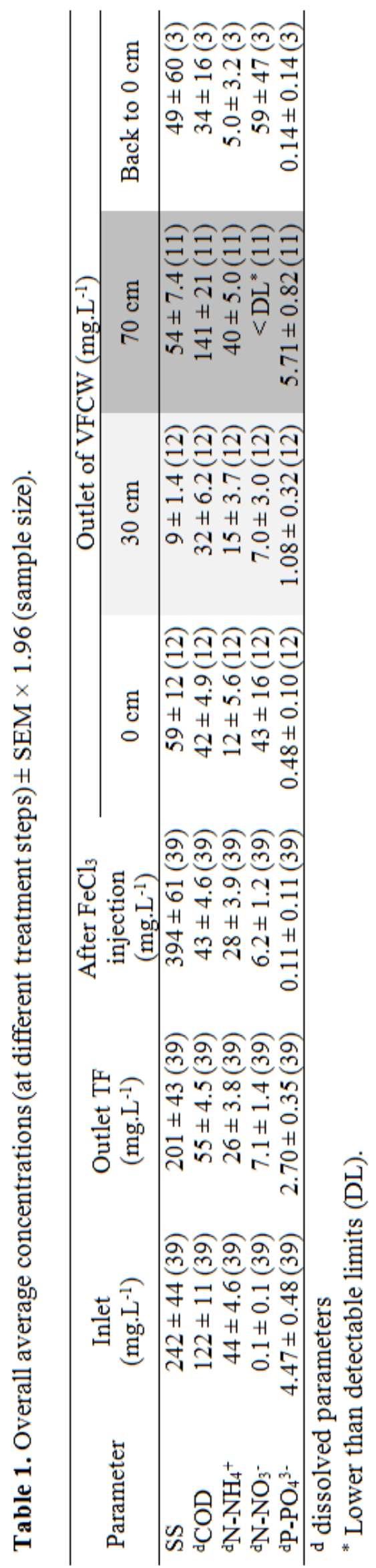


concentrations of the considered parameter expressed in percentage. Results are gathered in Table 2. The sum of dissolved ammonium and nitrate concentrations was used to calculate total dissolved nitrogen $\left(\left[\mathrm{NO}_{3}{ }^{-}+\mathrm{NH}_{4}{ }^{+}\right]-\mathrm{N}\right)$ removal.

Table 2. Overall removal rate $(\%)$ of the whole pilot-scale installation with different water saturation level within VFCW pilot expressed as Mean \pm SEM $\times 1.96$ (sample size).

\begin{tabular}{|c|c|c|c|}
\hline \multirow[t]{2}{*}{ Parameter } & \multirow{2}{*}{$\begin{array}{l}\text { Unsaturated VFCW } \\
\qquad 0 \mathrm{~cm}\end{array}$} & \multirow{2}{*}{$\begin{array}{c}\text { Partially saturated } \\
\text { VFCW } \\
30 \mathrm{~cm}\end{array}$} & \multirow{2}{*}{$\begin{array}{c}\text { Totally saturated } \\
\text { VFCW } \\
70 \mathrm{~cm}\end{array}$} \\
\hline & & & \\
\hline SS & $71.4 \pm 7.5(15)$ & $94.9 \pm 1.8(12)$ & $70.9 \pm 10.1(11)$ \\
\hline${ }^{\mathrm{d}} \mathrm{COD}$ & $69.4 \pm 5.5(15)$ & $69.6 \pm 6.0(11)$ & $-*$ \\
\hline${ }^{\mathrm{d}} \mathrm{N}-\mathrm{NH}_{4}{ }^{+}$ & $78.4 \pm 8.2(15)$ & $60.9 \pm 11.4(11)$ & $-^{* *}$ \\
\hline${ }^{\mathrm{d}} \mathrm{N}-\left[\mathrm{NO}_{3}^{-}+\mathrm{NH}_{4}^{+}\right]$ & $-{ }^{*}$ & $44.8 \pm 11.0(11)$ & $-^{* *}$ \\
\hline${ }^{\mathrm{d}} \mathrm{P}-\mathrm{PO}_{4}{ }^{3-}$ & $90.5 \pm 3.3(15)$ & $77.3 \pm 6.6(11)$ & $-*$ \\
\hline \multicolumn{4}{|c|}{ dissolved concentrations } \\
\hline \multicolumn{4}{|c|}{ * Negative removals indicating a production or release of concerned parameter. } \\
\hline \multicolumn{4}{|c|}{${ }^{* *}$ No significant differences (ANOVA, $p$ value > 0.05) between concentrations before and } \\
\hline
\end{tabular}

During unsaturated VFCW configuration, good removals of SS and dCOD were observed. As the whole treatment line was under aerobic condition, high nitrification rate with concomitant nitrate production were obtained. Excellent dissolved phosphate retention was also observed. Under partly saturated VFCW configuration, excellent SS removal rate was observed. Ammonium and dCOD removal rates were in the same order of magnitude as in the unsaturated phase. Dissolved TN removal rate increased, indicating the installation of denitrification process within water saturated zone.

Under flooded condition, only SS removal was observable. Releases of dissolved COD and phosphate were obtained, suggesting anaerobic biodegradation of organic matters. 


\subsection{Performance of trickling filter pilot and ferric chloride injection}

The results obtained for measured parameters at first three sampling points (Inlet-TF, OutletTF and Inlet-VFCW; Fig. 1) along the treatment line are shown in Fig. 2. The total number of monitoring was 38 and its results are presented by box plots which indicate the median (band inside the box), quartiles (top and bottom of the box), minimum and maximum values. In the first place, significant variations were observed at the inlet (untreated wastewater) for almost all parameters.

Regarding the trickling filter pilot, mean input-output removal rates, for dissolved COD, $\mathrm{NH}_{4}{ }^{+}-\mathrm{N}$ and $\mathrm{PO}_{4}{ }^{3-}-\mathrm{P}$ were $53 \%$ (SD: 12), $41 \%$ (SD: 19), and 40\% (SD: 15), respectively. For dissolved COD, the trickling filter allowed to smooth the relatively high variation of inlet concentrations. The removal of ammonium $\left(\mathrm{NH}_{4}{ }^{+}-\mathrm{N}\right)$ and production of nitrate $\left(\mathrm{NO}_{3}{ }^{-} \mathrm{N}\right)$ indicated the role of this first treatment step in the nitrification process. Finally, removal of dissolved $\mathrm{PO}_{4}{ }^{3-}-\mathrm{P}$ was also observed at this step of the treatment line, with about $40 \%$ (SD: 15) decrease of dissolved $\mathrm{PO}_{4}{ }^{3-}-\mathrm{P}$ concentration. This observation may partly be attributed to microbial consumptions within the bioreactor, and also to physicochemical sorption onto organic matters and/or residual iron species in the bottom of the pumping station.

Ferric chloride injection showed a good performance in P removal with an average of $98 \%$ (SD: 2). The residual total dissolved iron amounts were only $1.2 \%$ of total iron initially added. Almost all dissolved iron was therefore found to react with the reactive species during the treatment, indicating that the dosage of $\mathrm{FeCl}_{3}$ was not in large excess. 

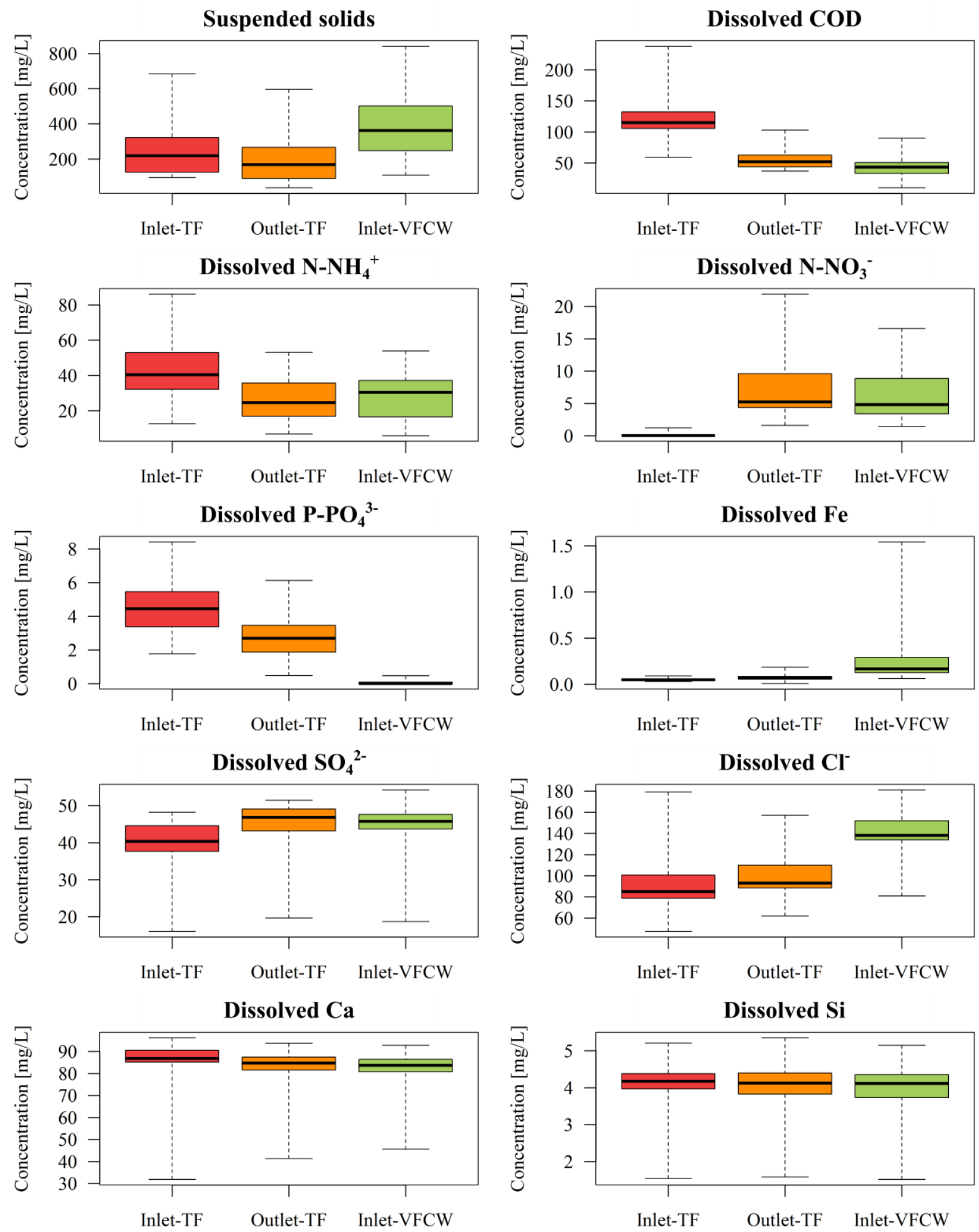

Fig. 2. Concentrations of different parameters at three different points along the process line: inlet of the trickling filter (Inlet-TF), outlet of the trickling filter (Outlet-TF; before $\mathrm{FeCl}_{3}$ injection) and inlet of the VFCW (Inlet-VFCW; after $\mathrm{FeCl}_{3}$ injection). 


\subsection{Performance of VFCW pilot}

\subsubsection{Influence of the water saturation level within the VFCW pilot}

The evolution of redox potential (Eh) at three different depths within the VFCW pilot during the study is shown in Fig. 3. Four different redox conditions were considered based on the approach followed in soil sciences (Diáková et al., 2006; Laanbroek, 1990; Reddy and D'Angelo, 1994; Szogi et al., 2004), namely: aerobic (oxygen reduction zone; > $300 \mathrm{mV}$ ), anoxic (nitrate and $\mathrm{Mn}^{4+}$ reduction zone; 100 to $300 \mathrm{mV}$ ), reduced $\left(\mathrm{Fe}^{3+}\right.$ reduction zone; -100 to $100 \mathrm{mV}$ ) and anaerobic (sulphate reduction zone; -200 to $-100 \mathrm{mV}$ ).

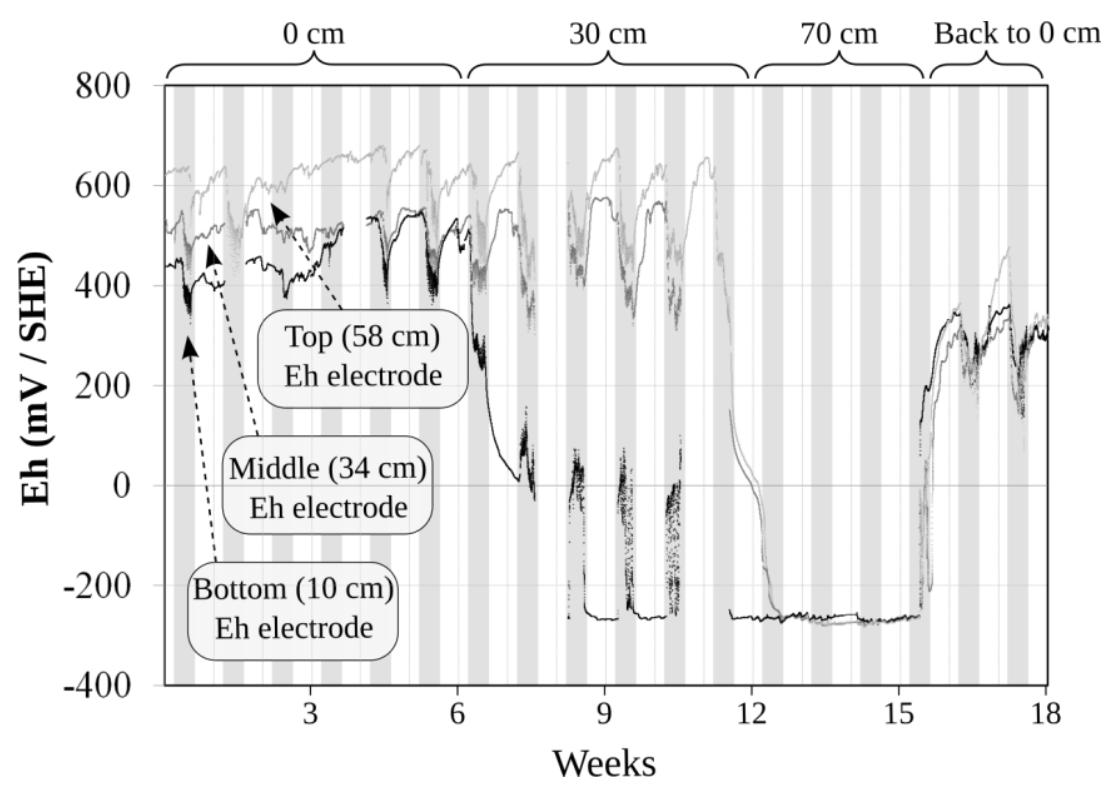

Fig. 3. Eh evolutions at three different depths of the VFCW during the successive phases for water level shown at the top. Grey and white vertical stripes indicate feeding and resting periods respectively.

The influence of the level of water saturation can be clearly observed. Under unsaturated conditions (first phase of the study), Eh ranging between 400 and $670 \mathrm{mV}$ were measured, indicating that aerobic conditions prevailed within the filter. During the second phase of the experiment (partly saturated conditions), the Eh measured at the bottom of the filter (within the saturated zone) decreased progressively down to $-250 \mathrm{mV}$ after 2 weeks, revealing 
anaerobic conditions. In the unsaturated upper part of the filter however, Eh remained between 400 and $670 \mathrm{mV}$ as previously, thereby confirming aerobic conditions. Finally in the last phase (flooding), Eh values at the top and the middle of the filter also decreased rapidly down to around $-250 \mathrm{mV}$ within one week, indicating that the whole filter was then under anaerobic conditions.

The influence of feeding and resting periods on the Eh within the VFCW was also clearly observed in Fig. 4. It can be seen that during feeding periods, the Eh values measured in the unsaturated zone decreased by approximately $200 \mathrm{mV}$, and a reverse phenomenon occurred in saturated zone as a consequence of the impact of fresh wastewater flowing in the different zones. This phenomenon was not observed during the flooded phase, suggesting the installation of anaerobic condition within the entire depth of the VFCW pilot which was unaffected by feeding and resting periods.

\subsubsection{Evolution of relevant parameters at each phase of the experiment}

Unlike the two previous treatment steps, the VFCW pilot was subjected to different environmental conditions (water saturation levels) along the experiment. Therefore, the monitored parameters around this pilot are discussed in four different phases according to redox condition changes over time. Inlet and outlet concentrations of SS, dCOD, $\mathrm{NH}_{4}{ }^{+}-\mathrm{N}$, $\mathrm{NO}_{3}{ }^{-}-\mathrm{N}, \mathrm{PO}_{4}{ }^{3-}-\mathrm{P}$, total iron $(\mathrm{Fe}), \mathrm{SO}_{4}{ }^{2-}$ and total manganese $(\mathrm{Mn})$ are shown in Fig. 4. This figure clearly highlighted that the water saturation level had influence on the observed results. Regarding suspended solids (SS), despite high variations of inlet concentration, quite stable and low outlet concentrations were maintained at the successive phases of the treatment line.

Outlet SS concentrations varied between 30-98 mg.L $\mathrm{L}^{-1}$, 4-13 mg.. $\mathrm{L}^{-1}$, and 26-69 mg. $\mathrm{L}^{-1}$ during unsaturated, partly saturated and flooded phases, respectively. The best SS removal rate (97.8\%) was found during partly saturated phase. It could be explained by a settling effect 
within the water saturated zone. For flooded phase, despite of an important height of water settling zone within the filter, SS removal rate decreased compare to the previous condition. This could be explained by a physical degradation of organic matters within the sludge layer due to anaerobic conditions.

Regarding dissolved COD and ammonium, their outlet concentrations varied within similar ranges under unsaturated and partly saturated conditions (11-58 mg. $\mathrm{L}^{-1}$ and $1.7-27.7 \mathrm{mg} . \mathrm{L}^{-1}$ respectively). On the other hand, during the flooded phase, the outlet concentration of both dissolved COD and ammonium were found to increase, suggesting degradation of some organic matters under anaerobic condition. This observation could indicate a negative performance of the filter due to the extreme conditions simulating a severe malfunctioning of the system. However, when aerobic conditions were re-established by draining the filter at the end of the 4-week flooded phase, the concentrations of both parameters rapidly decreased, thereby revealing the good resilience of the system. Two hypotheses may be proposed to explain this good resilience of the VFCW pilot:

- a rapid recovery of the activity of facultative aerobic bacteria after inhibition by flooding.

- a continuous provision of aerobic bacteria from the trickling filter.

For nitrates concentrations, strong increases were observed between inlet and outlet during the unsaturated phase. In addition, very high concentrations of nitrates at the beginning of feeding periods were noted. This phenomenon could be explained by a continuous nitrification during resting period causing discharges of organic nitrogen and adsorbed ammonium within the sludge layer of VFCW pilot (Morvannou et al., 2014). Starting from the very beginning of the partly saturated phase, a decrease of outlet nitrate concentrations was observed while outlet ammonium concentrations stayed stable: the nitrates formed by nitrification were denitrified in the saturated zone. On the other hand, during the flooded 
phase, no more nitrates were detected at the outlet because of lack of nitrification. Once the unsaturated zone re-established, an observable production of nitrates after one week can be seen.

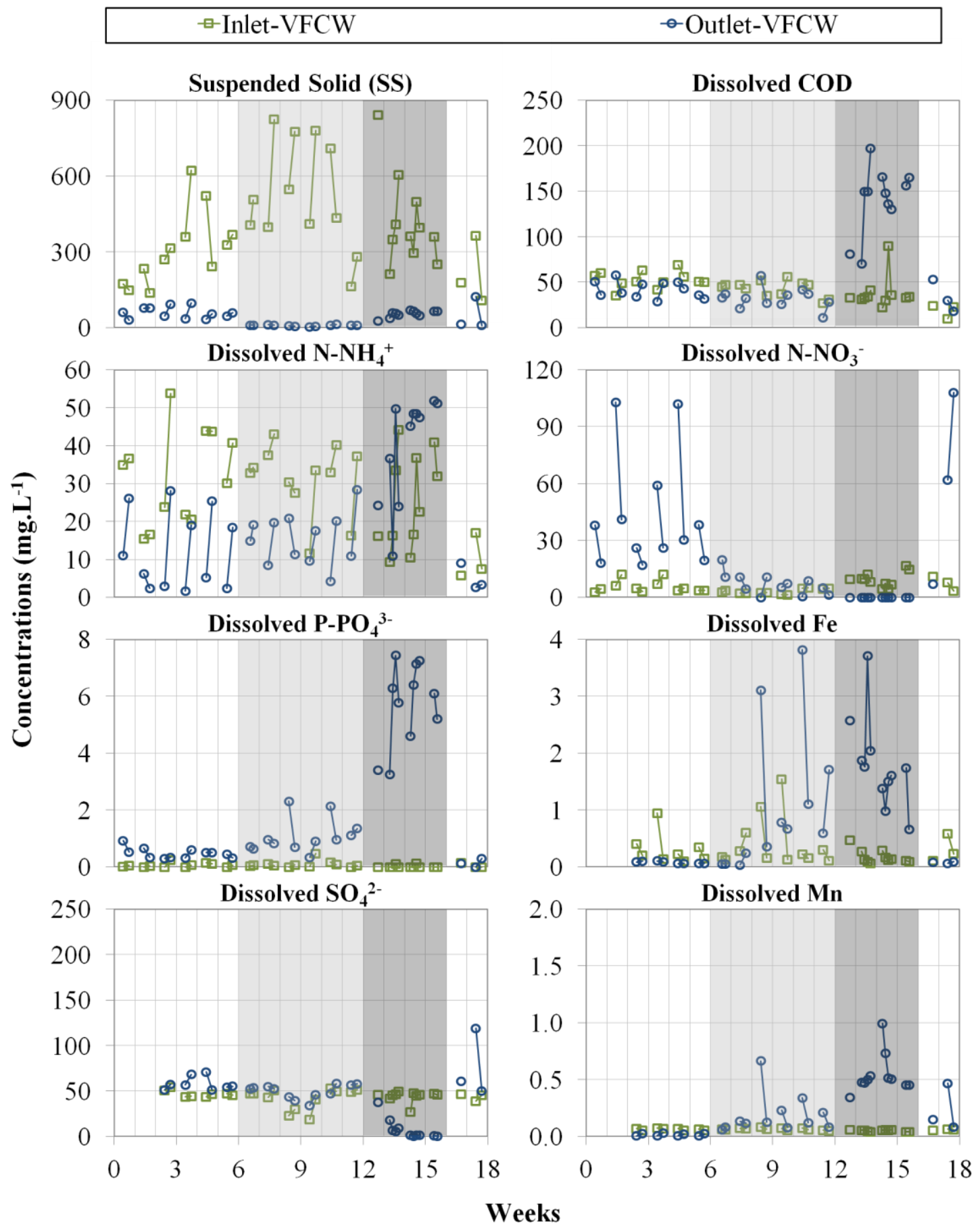

Fig. 4. Concentrations of different parameters at inlet/outlet of the VFCW pilot. White, light grey and grey background colours respectively represent unsaturated, partially saturated and flooded phases of the study. 
Finally, Fig. 4 shows that dissolved phosphate outlet concentration varied between 0.30$0.93 \mathrm{mg} . \mathrm{L}^{-1}, 0.34-2.31 \mathrm{mg} . \mathrm{L}^{-1}$, and 3.25-7.44 mg. $\mathrm{L}^{-1}$ under unsaturated, partly saturated and flooded conditions respectively. The fact that $\mathrm{P}$ concentration increased during the partly saturated phase indicated firstly the presence of P species at the bottom of the VFCW pilot, suggesting the vertical transfer of $\mathrm{P}$ species through the porous medium from the surface sludge layer to the bottom of the VFCW. Secondly this observation also showed that reduced conditions within this zone induced the solubilisation of present $\mathrm{P}$ species. Dissolved iron concentration followed a similar pattern (as also Mn concentration) as $\mathrm{P}$ during the first two phases (unsaturated and partly saturated VFCW pilot), suggesting the dissolution of reduced iron species, with concomitant $\mathrm{P}$ releases. Numerous studies reported the release of $\mathrm{P}$ by the reductive dissolution of P-bearing ferric species (Hantush et al., 2013; Moustafa et al., 2012; Patrick and Khalid, 1974; Shenker et al., 2005).

On the other hand, the strong release of P during the flooded phase was not accompanied by an equivalent increase of iron release at the outlet of VFCW pilot. Furthermore, decrease of dissolved iron concentration was even observed after two weeks of flooded phase. This observation could suggest that the conditions within the filter induced the precipitation of solubilised iron species. For example, the presence of sulphides probably caused $\mathrm{FeS}$ formation as already described by other authors (Chen et al., 2013; Erler et al., 2011; Jakobsen and Postma, 1999). Indeed, due to the anaerobic conditions (Eh below $-250 \mathrm{mV}$ ), sulphides were likely produced by sulphate reducing anaerobic bacteria. Fig. 4 shows that dissolved sulphate outlet concentrations were relatively stable during unsaturated and partly saturated phases, but decreased down to very low concentrations during the flooded phase, thereby confirming the hypothesis of sulphate reduction. 
When aerobic conditions were re-established at the end of the 4-week flooded phase, the outlet concentrations of dissolved phosphate and iron rapidly decreased, confirming the good resilience of the system.

\subsection{Principal components analysis (PCA) of the data gathered for the VFCW pilot}

In order to investigate the influence of the redox conditions measured at three different depths of the pilot on the numerous parameters followed in the study, a principal components analysis (PCA) was performed. Preliminary study (results not shown) allowed to select 9 relevant parameters for the final analysis, namely: Eh values measured at the bottom, middle and surface of the filter (Eh.B, Eh.M, Eh.S respectively), VFCW pilot outlet concentrations for SS, dCOD, ammonium, nitrate, phosphate and iron (SS, dCOD, NH4-N, NO3-N, PO4-P and Fe, resp.). According to the results of PCA, only first two principal components had statistically significant Eigen values (> 1) and they accounted for $80.7 \%$ of the inertia. Therefore, the analysis shown below refers only to these two components which were considered to be sufficiently informative.

Fig. 5 shows selected parameters on the correlations circle (a) and a plot of individual data points (b) on the plane represented by the two first principal component axes. A supplementary quantitative variable representing the water saturation level (WSL) within the VFCW pilot was also shown on the correlation circle in Fig. 5 (a). This variable did not participate to PCA because it was the only controlled variable along the whole experiment. Each parameter appeared close to the correlation circle, indicating that they were well represented. 


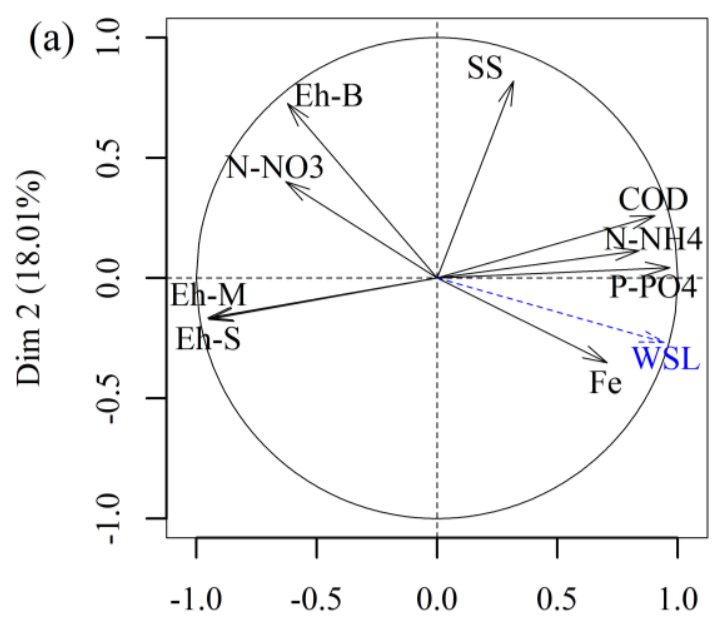

$\operatorname{Dim} 1(62.72 \%)$

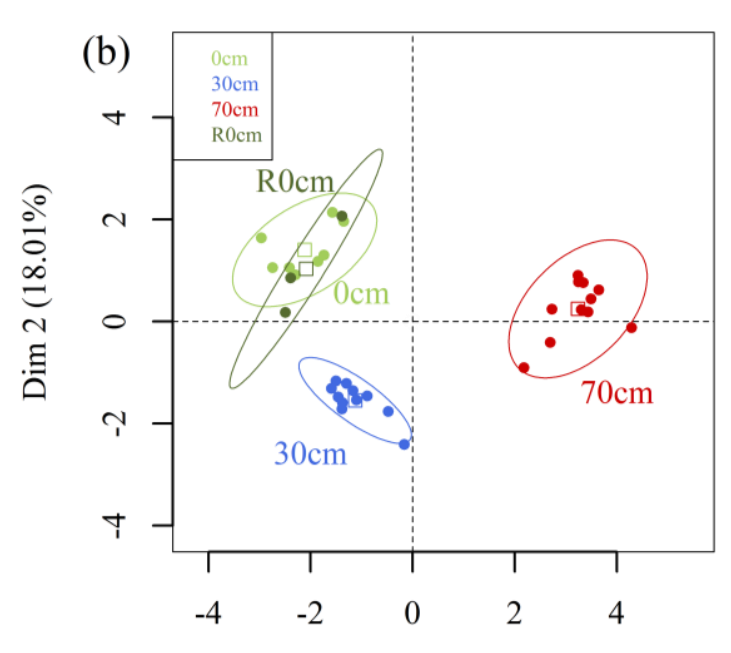

$\operatorname{Dim} 1(62.72 \%)$

Fig. 5. PCA plots in the subspace defined by the first two principal components: (a) variables and correlation circle (supplementary variable is shown with the dotted arrows); (b) individual data, illustrating different water saturation level (WSL) within the VFCW pilot $(0 \mathrm{~cm}, 30 \mathrm{~cm}, 70 \mathrm{~cm}$ and return to $0 \mathrm{~cm}[\mathrm{R} 0 \mathrm{~cm}]$, resp.).

First of all, it can be seen that the redox potentials at the surface and in the middle of the VFCW pilot varied together. Among the parameters of water analyses, only outlet concentration of SS seemed to be independent of the redox conditions within the VFCW pilot. Nitrates outlet concentration was positively correlated with the Eh at the bottom of the filter.

Releases of dissolved iron and phosphate were found to be negatively correlated with the combination of redox conditions within the entire depth of VFCW pilot, thereby confirming the reduction of P-bearing ferric species as a significant mechanism of $\mathrm{P}$ release in the studied system. The fact that the dissolved iron release was not as much anti-correlated to the surface Eh as $\mathrm{P}$ release could be explained by $\mathrm{FeS}$ formation under anaerobic condition as described before (cf. 3.3.2). However, this observation may also suggest other mechanisms of $\mathrm{P}$ release in the VFCW pilot. Release of organic $\mathrm{P}$ may have occurred from the autolysis of 
strictly aerobic bacterial cells due to the brutal shift to anaerobic conditions (Turner et al., 2003), or from the anaerobic breakdown of organic nitrogen and phosphorus compounds (Reddy and D’Angelo, 1994). Strong negative correlations between the surface Eh and releases of dissolved COD, ammonium and phosphate could support this hypothesis.

The plot of individual data points (Fig. 5, b) revealed the existence of 3 distinct groups of data, defined with respect to water saturation level within the VFCW: $0 \mathrm{~cm}, 30 \mathrm{~cm}$ and $70 \mathrm{~cm}$. In addition, the point representing the return to unsaturated condition $[\mathrm{R} 0 \mathrm{~cm}]$ joined the initial unsaturated $[0 \mathrm{~cm}]$ data group. This could also indicate indirectly a good resilience of the VFCW pilot.

\section{Conclusion}

This study was conducted at the pilot scale to determine the influence of water-saturation level on redox conditions within the VFCW and on the treatment efficiency with specific attention to P retention. Redox potentials monitored at three different depths clearly showed time-course changes of Eh according to water saturation levels and feeding-resting cycles. Statistical analysis of experimental data using PCA showed that Eh was the key parameter controlling phosphorus release from the sludge.

When the VFCW was under aerobic condition (unsaturated phase), significant nitrification and a low release of dissolved P were observed. During the following experimental phase, when the VFCW was partly saturated, a decrease of the Eh was observed at the bottom of the VFCW (saturated zone) about 2 weeks after the experimental condition was changed from unsaturated to partly saturated. During this phase, very good performance in SS removal and denitrification were observed. On the other hand, iron reduction with concomitant $\mathrm{P}$ release $\left(1.08 \pm 0.57 \mathrm{mg} \mathrm{P.L^{-1 }}\right)$ was observed. Since only the bottom part of the VFCW was saturated in this experimental phase, the migration of $\mathrm{P}$ species from the surface sludge layer to the 
bottom of the VFCW but also suggested that the reduction of P-bearing ferric species was a significant mechanism of $\mathrm{P}$ release.

In the last experimental phase, when the VFCW pilot was completely flooded (including the surface sludge layer), one week was needed until anaerobic conditions were established in the whole depth. During this phase, the performance of the VFCW declined for all parameters. While dissolved $\mathrm{P}$ release increased, dissolved iron release did not exhibit an equivalent increase. This could suggest either the re-precipitation of reduced iron species (due for example to $\mathrm{FeS}$ formation) and/or the occurrence of other mechanisms of $\mathrm{P}$ release such as the autolysis of strictly aerobic bacterial cell material due to the shift to anaerobic conditions. Flooded conditions should therefore be avoided in practice to prevent phosphate release. However, in this study, a sharp increase in the dissolution of Fe-bound phosphates was observed only after one whole week of flooding. This delay maybe attributed to the role of the trickling filter which provided relatively stable sludge organic matters but also non negligible quantities of nitrates to the VFCW. A fresh biodegradable sludge would probably have caused a higher consumption of oxygen resulting in a more rapid Eh drop and phosphates dissolution. These phenomena would have been accelerated without the nitrates provided by the trickling filter. Therefore, in the present study, the use of a trickling filter as pretreatment stage contributed to the good resistance of the system to unfavourable conditions as flooding.

Finally, when the whole water within the VFCW was drained out at the end of the experiment, aerobic conditions and good treatment efficiency were rapidly re-established, underlining that VFCW was resilient enough that the changes in the saturation level affected its performance only temporarily. 


\section{Acknowledgements}

Financial support for this work was provided by SCIRPE and CIFRE (Conventions Industrielles de Formation par la REcherche). The authors wish to thank O. Collache, R. Poncet and H. Perier-Camby for the installation of the pilot system and redox potential measurements equipments. They are also grateful to N. Dumont and D. Lebouil of LGCIE for chemical analyses (ICP-AES and ion chromatography) and to reviewers for their contribution to improvement of this manuscript.

\section{References}

Abou-Elela, S.I., Golinielli, G., Abou-Taleb, E.M. and Hellal, M.S., 2013. Municipal wastewater treatment in horizontal and vertical flows constructed wetlands. Ecological Engineering. 61, Part A, 460-468.

AFNOR, 2005. Recueil Normes et Réglementation Environnement., Qualité de l'eau, Vol 1 (p552), Vol 2 (p502).

Brix, H. and Arias, C.A., 2005. The use of vertical flow constructed wetlands for on-site treatment of domestic wastewater: New Danish guidelines. Ecological Engineering. 25 (5), 491-500.

Chen, T.-H., Wang, J., Zhou, Y.-F., Yue, Z.-B., Xie, Q.-Q. and Pan, M., 2014. Synthetic effect between iron oxide and sulfate mineral on the anaerobic transformation of organic substance. Bioresource Technology. 151, 1-5.

Diáková, K., Holcová, V., Šíma, J. and Dušek, J., 2006. The Distribution of Iron Oxidation States in a Constructed Wetland as an Indicator of Its Redox Properties. Chemistry \& Biodiversity. 3 (12), 1288-1300.

Erler, D.V., Tait, D., Eyre, B.D. and Bingham, M., 2011. Observations of nitrogen and phosphorus biogeochemistry in a surface flow constructed wetland. Science of The Total Environment. 409 (24), 5359-5367.

Faulwetter, J.L., Gagnon, V., Sundberg, C., Chazarenc, F., Burr, M.D., Brisson, J., Camper, A.K. and Stein, O.R., 2009. Microbial processes influencing performance of treatment wetlands: A review. Ecological Engineering. 35 (6), 987-1004.

Hantush, M., Kalin, L., Isik, S. and Yucekaya, A., 2013. Nutrient Dynamics in Flooded Wetlands. I: Model Development. Journal of Hydrologic Engineering. 18 (12), 17091723.

Heistad, A., Paruch, A.M., Vråle, L., Ádám, K. and Jenssen, P.D., 2006. A high-performance compact filter system treating domestic wastewater. Ecological Engineering. 28 (4), 374379.

Jakobsen, R. and Postma, D., 1999. Redox zoning, rates of sulfate reduction and interactions with Fe-reduction and methanogenesis in a shallow sandy aquifer, Røm $\varnothing$, Denmark. Geochimica et Cosmochimica Acta. 63 (1), 137-151. 
Kadlec, R., Knight, R., Vymazal, J., Brix, H., Cooper, P. and Haberl, R., 2000. Constructed Wetlands for Pollution Control. IWA Publishing.

Kim, B., Gautier, M., Michel, P. and Gourdon, R., 2013. Physical-chemical characterization of sludge and granular materials from a vertical flow constructed wetland for municipal wastewater treatment. Water Science \& Technology. 68 (10).

Kim, B., Gautier, M., Molle, P., Michel, P., Prost-Boucle, S., Colombet, D. and Gourdon, R., 2012. Field study of wastewater treatment with partially flooded vertical-flow constructed wetlands using AZOE® process. In: Proceedings of the 13th International Conference on Wetland Systems for Water Pollution Control, Perth, Australia. 377-384.

Laanbroek, H.J., 1990. Bacterial cycling of minerals that affect plant growth in waterlogged soils: a review. Aquatic Botany. 38 (1), 109-125.

Lowe, E.F. and Keenan, L.W., 1997. Managing phosphorus-based, cultural eutrophication in wetlands: a conceptual approach. Ecological Engineering. 9 (1-2), 109-118.

Martín, M., Gargallo, S., Hernández-Crespo, C. and Oliver, N., 2013. Phosphorus and nitrogen removal from tertiary treated urban wastewaters by a vertical flow constructed wetland. Ecological Engineering. 61, Part A, 34-42.

Molle, P., Liénard, A., Boutin, C., Merlin, G. and Iwema, A., 2005. How to treat raw sewage with constructed wetlands: an overview of the French systems. Water Science \& Technology. 51 (9), 11-21.

Molle, P., Liénard, A., Grasmick, A. and Iwema, A., 2006. Effect of reeds and feeding operations on hydraulic behaviour of vertical flow constructed wetlands under hydraulic overloads. Water Research. 40 (3), 606-612.

Molle, P., Martin, S., Esser, D., Besnault, S., Morlay, C. and Harouiya, N., 2011. Phosphorus removal by the use of appatite in constructed wetlands: Design recommendations. Water Practice \& Technology. 6 (3).

Molle, P., Prost-Boucle, S. and Lienard, A., 2008. Potential for total nitrogen removal by combining vertical flow and horizontal flow constructed wetlands: A full-scale experiment study. Ecological Engineering. 34 (1), 23-29.

Morvannou, A., Choubert, J.-M., Vanclooster, M. and Molle, P., 2014. Modeling nitrogen removal in a vertical flow constructed wetland treating directly domestic wastewater. Ecological Engineering. 70, 379-386.

Moustafa, M.Z., White, J.R., Coghlan, C.C. and Reddy, K.R., 2012. Influence of hydropattern and vegetation on phosphorus reduction in a constructed wetland under high and low mass loading rates. Ecological Engineering. 42, 134-145.

Murphy, J. and Riley, J.P., 1962. A modified single solution method for the determination of phosphate in natural waters. Analytica Chimica Acta. 27 (0), 31-36.

Patrick, W.H. and Khalid, R.A., 1974. Phosphate Release and Sorption by Soils and Sediments: Effect of Aerobic and Anaerobic Conditions. Science. 186 (4158), 53-55.

Prigent, S., Belbeze, G., Paing, J., Andres, Y., Voisin, J. and Chazarenc, F., 2013. Biological characterization and treatment performances of a compact vertical flow constructed wetland with the use of expanded schist. Ecological Engineering. 52, 12-18.

Prochaska, C.A., Zouboulis, A.I. and Eskridge, K.M., 2007. Performance of pilot-scale vertical-flow constructed wetlands, as affected by season, substrate, hydraulic load and frequency of application of simulated urban sewage. Ecological Engineering. 31 (1), 57 66. 
Reddy, K.R. and D'Angelo, E.M., 1994. Soil precesses regulating water quality in wetlands., in: Mitsch, W.J. (Ed.), Global Wetlands. Old World and New. ElseVier, Amsterdam, Lausanne, New York, Oxford, Shonnon, Tokyo, pp. 309-324.

Reddy, K.R. and D'Angelo, E.M., 1997. Biogeochemical indicators to evaluate pollutant removal efficiency in constructed wetlands. Water Science \& Technology. 35 (5), 1-10.

Schindler, D.W., 1977. Evolution of Phosphorus Limitation in Lakes. Science. 195 (4275), 260-262.

Shenker, M., Seitelbach, S., Brand, S., Haim, A. and Litaor, M.I., 2005. Redox reactions and phosphorus release in re-flooded soils of an altered wetland. European Journal of Soil Science. 56 (4), 515-525.

Szogi, A.A., Hunt, P.G., Sadler, E.J. and Evans, D.E., 2004. Characterization of oxidationreduction processes in constructed wetlands for swine wastewater treatment. Applied Engineering in Agriculture. 20, 189-200.

Tiessen, H., 2008. Phosphorus in the global environment, in: White, P.J. and Hammond, J.P. (Ed.), The Ecophysiology of Plant-Phosphorus Interactions. Springer Netherlands, pp. 17.

Torrens, A., Molle, P., Boutin, C. and Salgot, M., 2009. Impact of design and operation variables on the performance of vertical-flow constructed wetlands and intermittent sand filters treating pond effluent. Water Research. 43 (7), 1851-1858.

Turner, B.L., Driessen, J.P., Haygarth, P.M. and McKelvie, I.D., 2003. Potential contribution of lysed bacterial cells to phosphorus solubilisation in two rewetted Australian pasture soils. Soil Biology and Biochemistry. 35 (1), 187-189.

Veneman, P.L.M. and Pickering, E.W., 1983. Salt bridge for field redox potential measurements. Communications in Soil Science and Plant Analysis. 14 (8), 669-677.

Verhoeven, J.T.A. and Meuleman, A.F.M., 1999. Wetlands for wastewater treatment: Opportunities and limitations. Ecological Engineering. 12 (1-2), 5-12.

Vohla, C., Kõiv, M., Bavor, H.J., Chazarenc, F. and Mander, Ü., 2011. Filter materials for phosphorus removal from wastewater in treatment wetlands-A review. Ecological Engineering. 37 (1), 70-89.

Vymazal, J., 2005. Horizontal sub-surface flow and hybrid constructed wetlands systems for wastewater treatment. Ecological Engineering. 25 (5), 478-490. 